\title{
Shear Tests and Calculation of Shear Resistance with the PC Program RFEM from Thin Partition Walls of Brick in Old Buildings
}

\author{
Sinan Korjenic ${ }^{1}$, Bernhard Nowak ${ }^{1}$, Philipp Löffler ${ }^{1}$, Anna Vašková ${ }^{2}$ \\ ${ }^{1}$ Vienna University of Technology \\ Faculty of Civil Engineering, Institute for Building Construction and Technology, \\ Research Centre for building construction and building maintenance \\ E-Mail: sinan.korjenic@tuwien.ac.at \\ ${ }^{2}$ Technical University of Košice, Faculty of Civil Engineering, \\ Institute of Architectural Engineering, Department of Building Physics \\ E-mail: anna.vaskova@tuke.sk
}

\begin{abstract}
This paper is about the shear capacity of partition walls in old buildings based on shear tests which were carried out under real conditions in an existing building. There were experiments conducted on different floors and in each case, the maximum recordable horizontal force and the horizontal displacement of the respective mortar were measured. At the same time material studies and material investigations were carried out in the laboratory. The material parameters were used for the calculation of the precise shear capacity of each joint. In the shear tests, the maximum displacement of a mortar joint was determined at a maximum of two to four millimetres. Furthermore, no direct linear relationship between the theoretical load (wall above it) and the shear stress occurred could be detected in the analysis of the experiment, as it was previously assumed.
\end{abstract}

Key words: shear capacity, shear stress, shear test, horizontal force, lime mortar

\section{Introduction}

During alterations in old objects, dividing walls (mostly thin non-load-bearing walls) are often removed entirely or partially cancelled in order to obtain either a new passage, or a new layout. Here arises for some time the question of what role a partition wall in the structural behaviour of an old object, in case of horizontal load (e.g. wind) or an exceptional load plays (such as earthquakes). That an old building without partition walls can withstand an earthquake is to be doubted, since all horizontal loads would have to be derived over the fire walls into the foundation. In practice this is not possible because the wooden ceilings are to be regarded as not rigidly (or have only a low shear stiffness) and therefore the horizontal loads 
cannot be forwarded to the fire wall [1]. One subject that intensively concerns engineers and architects, currently in terms of constructions in existing buildings - such as Wilhelminian style houses - is the evaluation of these properties in the case of adaptations, refurbishments or extensions with regard to their stability at an extraordinary action (such as earthquakes). On May 2013, a new set of rules in Austria, namely the ONR 24009 "assessment of the sustainability of existing buildings" [5] entered in force, which should be considered together with the ÖNORM B 1998-3 and EN 1998-3. The content of this standard claims, among other things, that the overall risk of an existing building, if adaptations or renovations are made (e.g. ground floor renovation), the use is changed (e.g. kindergarten group in place of an apartment), or the object is extended (e.g.: loft conversion), must correspond to the needs that would arise if you built a building on a "greenfield site". At the same time a minimum of security is required, which existing structures must reach, if they are adapted - the so-called minimum capacity [7].

\section{Intermediate walls in houses of Wilhelminian style}

The typical outline of a Wilhelminian style house (see Fig. 5 and 6) consists of three constructive load, solid walls (roadside outer wall, centre wall and courtyard side exterior wall - thicknesses from 45 to $120 \mathrm{~cm}$ ). There are two fire walls, which usually have a thickness of $30 \mathrm{~cm}$ along the boundary [10]. Since it was recognized early on that these walls are not sufficient for the stiffener, so-called thin mostly non-load-bearing intermediate walls were built. These usually have a thickness of $14 \mathrm{~cm}$ and on one hand form the separation between two apartments and on the other hand a separation between two single rooms [9]. Typical for Wilhelminian style houses is the over all floors same floor plan, that means that the intermediate walls were bricked on all floors one above the other. The exterior walls and intermediate stiffening walls have usually been constructed at the same time. This resulted in a connection or an indentation of these two components. From the geometry of the running bond - the rows are arranged staggered - arises in most cases, that every second brick connects the load-bearing wall and the intermediate wall [8]. A further characteristic of the intermediate walls is that in most cases no link between the intermediate walls and the individual ceiling was prepared. On both sides a narrower wooden beam was added with a few centimetre's distance from the intermediate wall [6].

\section{Calculating the maximum shear capacity according to EN and ÖNORM}

In principle, the calculation of the shear resistance is regulated in the EN 1996 and in ÖNORM EN 1996-1-1 [3] or the Austrian application document ÖNORM B 1996-1-1 [4]. According to [3] that the applied shear force $V_{E d}$ must be less than or equal to the design value of the shear capacity $V_{\mathrm{Rd}}$ :

$$
V_{E d} \leq V_{R d}
$$

Whereby the design value of the shear resistance is calculated using the following formula:

$$
V_{R d}=f_{v d} * t * l_{c}
$$


The boundary condition of the maximum shear capacity must be determined according to [3] using the following formula

$$
f_{v k}=f_{v k 0}+0,4 * \sigma_{d}
$$

However

$$
f_{v k}<0,065 f_{b} \text { bzw. } f_{v l t}
$$

The characteristic adhesive shear strength $f_{v k 0}$ can be seen from Table 1 below. Linearly interpolation is allowed between the values M1 and M2, which has been done in the test evaluation.

\begin{tabular}{|c|c|c|c|c|}
\hline Brick art & \multicolumn{2}{|c|}{$\begin{array}{l}\text { Normal mortar with a } \\
\text { Strength class }{ }^{\text {a }}\end{array}$} & $\begin{array}{l}\text { Thin-film mortar (bed joint } \\
\text { thick-ness } 0.5 \mathrm{~mm} \text { to } 3 \mathrm{~mm} \text { ) }\end{array}$ & $\begin{array}{l}\text { Light- } \\
\text { weight } \\
\text { mortar }\end{array}$ \\
\hline \multirow{3}{*}{ Brick } & $\geq \mathrm{M} 10$ & 0.30 & \multirow{3}{*}{0.30} & \multirow{11}{*}{0.15} \\
\hline & M2 & 0.20 & & \\
\hline & M1 & 0.10 & & \\
\hline \multirow{3}{*}{$\begin{array}{l}\text { Calcareous } \\
\text { sandstone }\end{array}$} & $\geq \mathrm{M} 10$ & 0.20 & \multirow{3}{*}{0.40} & \\
\hline & M2 & 0.15 & & \\
\hline & M1 & 0.10 & & \\
\hline \multirow{3}{*}{ Concrete } & $\geq \mathrm{M} 10$ & 0.20 & \multirow{5}{*}{0.30} & \\
\hline & M2 & 0.15 & & \\
\hline & M1 & 0.10 & & \\
\hline Aerated concrete & M2 to M10 & 0.15 & & \\
\hline $\begin{array}{l}\text { True to dimensions } \\
\text { natural stone }\end{array}$ & $\mathrm{M} 1$ to $\mathrm{M} 2$ & 0.10 & & \\
\hline
\end{tabular}

Tab. 1: Values for the initial shear strength $\mathrm{f}_{\mathrm{vk} 0}$ of masonry [4]

a Intermediate values for mortar strength of M1 to M10 are to interpolate linearly. For mortar strength under M1 the approach of an initial shear strength is not allowed.

\section{Experiment setup}

The preparations of the experiments (cut 2 wall openings, 2 "windows") claimed some time. The experiment itself (force applying to failure- shift state) can then be carried out in a few minutes. First, the plaster was knocked off a large area, so that a suitable site for the experimental setup could be found on one side of the intermediate wall. In the experiments, two juxtaposed wall openings were prepared, which were separated by an approximately 50 to $60 \mathrm{~cm}$ long brick pillar. The aim was to move this remaining brick pillar, by applying a horizontal load. For load generation, a small hydraulic pump (press) was used, which was 
controlled by a manual pump. The height of this brick pillar was elected with three droves because it so was intervening as little as possible with the stock and this height corresponded exactly with the height of the test equipment. Through the application of a horizontal load the uppermost and lowermost groove of this pillar eventually failed. Through the required force, the vertical force acting in the pillars can be recalculated. This arises from the relationship which is governed by the ÖNORM. The counter bearing is the centre wall / outer wall, or if it is not otherwise possible, a relatively long intermediate wall disk.
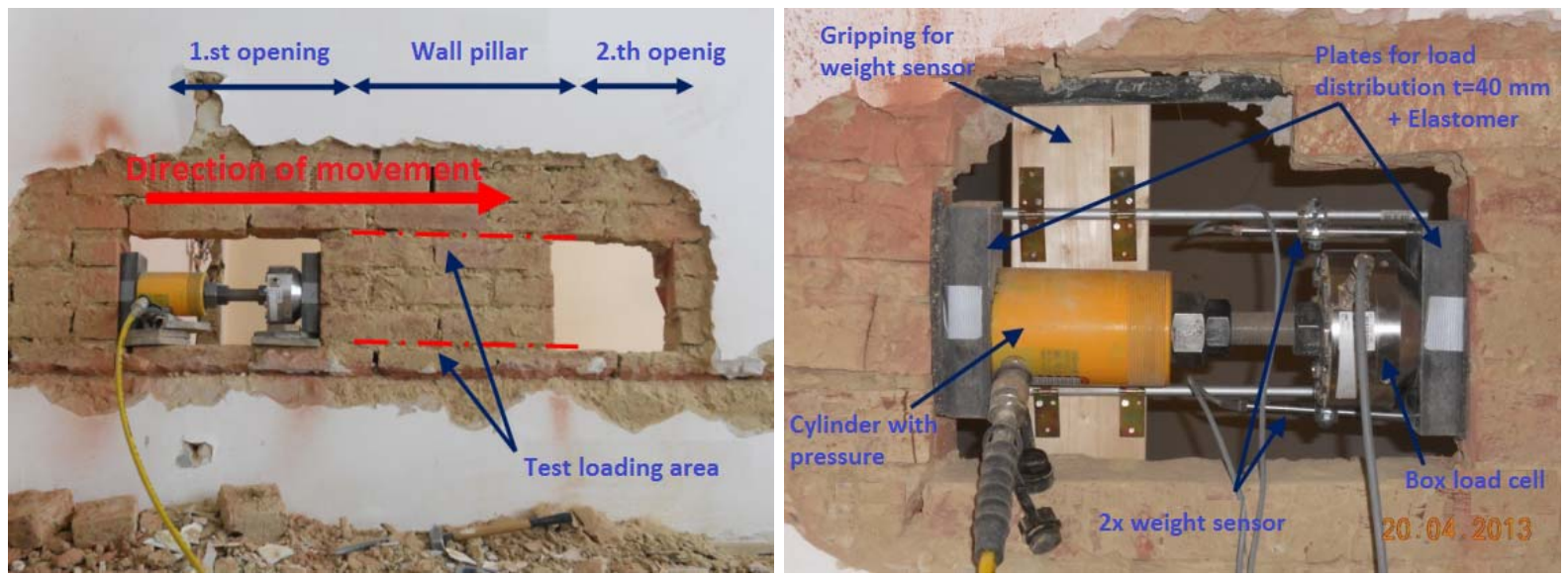

Figure 1: Test setup - two openings in the bracing intermediate walls (left) and experimental arrangement in the wall opening (right)
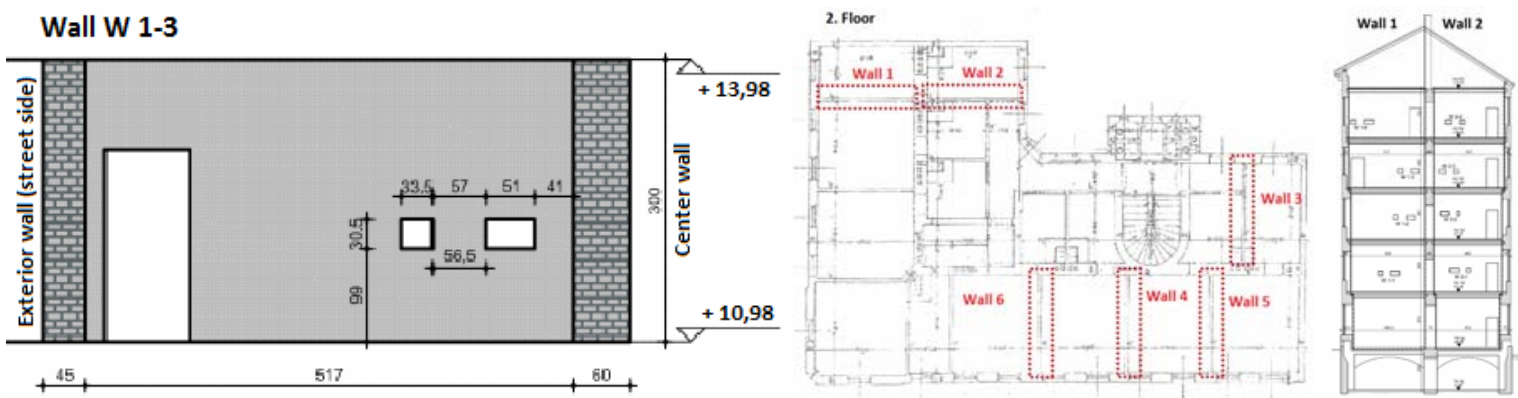

Figure 4: Wall view W1-3 with real dimensions, Figure 5: Overview of experimental walls on the 2nd floor and Figure 6: Overview - Wall $1 \& 2$

\section{Evaluation of the tests}

Tests have been carried out on different intermediate walls on different floors. The goal was to detect the maximum force that occurs when the horizontal shear capacity is exceeded out. The displacement was measured by two digital displacements transducers, the power by a digital load cell (force transducer), recorded time-dependent (simultaneously). As part of the planned renovations for the great restoration ("base redevelopment") with additional loft 
extension some intermediate walls are removed, whereby we were given the opportunity to carry out the tests in these walls (see Fig.5 and 6).
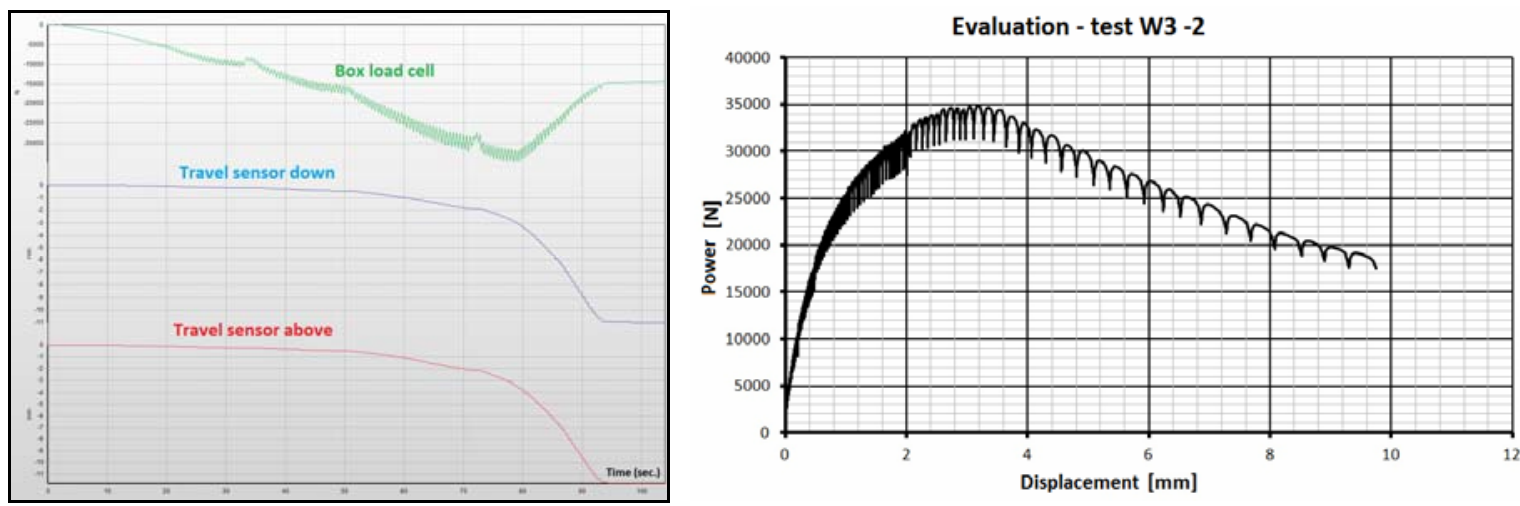

Figure 7: Recording logs wall 3, 2nd floor and Figure 8: Wall 3, 2nd floor - measured values (a common example)

\section{Calculation of the trials shear capacity with the PC program RFEM}

The calculation of the experimental shear resistance consists of two factors, the initial shear strength and friction of the respective load of the floors above the tested wall. The initial shear strength can be seen from Table 1 or either determined by experiments. At the experiments, it must be ensured that the material structure of the mortar or the bond between brick and mortar is not disturbed by the experimental setup and the experimental procedure. Under normal circumstances, at a construction site, it is not possible to determine these parameters. Thus, the values of the ÖNORM were used for further calculations, the exact value was interpolated, as a very accurate calculation of the mortar compressive strength of each sampling site was determined. For the test, the maximum shear capacity of a fugue revealed. From the formula for the characteristic shear resistance (see point 3) and the initial shear strength (mortar compressive strength [2]), the applied load can be deduced.

Example Wall 1 - 3rd floor:

1. Max. Force attempt $34.24 \mathrm{kN}$

2. Joint length: $57 \mathrm{~cm}$ (bottom) $+56.5 \mathrm{~cm}($ top $)=113.5 \mathrm{~cm}$, joint width: $14 \mathrm{~cm}$

3. Initial shear strength: $f_{v k 0}=0.0125 \mathrm{KN} / \mathrm{cm}^{2}$

4. Shear strength of the masonry: $f_{v k}=0.02155 \mathrm{kN} / \mathrm{cm}^{2}$

5. Normal stress: $\sigma_{\mathrm{k}}=0.02262 \mathrm{kN} / \mathrm{cm}^{2}$

6. Load on the pillars per meter: $31.67 \mathrm{kN} / \mathrm{m}$

\section{Determination of compressive load with RFEM}

In addition to the consideration of the test results, the individual panels were modelled and evaluated by means of the PC program RFEM. The calculation results can be directly 
compared with the experimental results. As model parameters, the following values were chosen according to [1]:

$E_{X}=2.000 \mathrm{~N} / \mathrm{mm}^{2} ; E_{Y}=4.000 \mathrm{~N} / \mathrm{mm}^{2} ; G_{X Y}=1.500 \mathrm{~N} / \mathrm{mm}^{2} ; \gamma=22 \mathrm{KN} / \mathrm{m}^{3} ; \vartheta_{X Y}=0.30$

\section{Reduction factor by experiment}

Due to the experimental setup load rearrangements are occurring in a homogeneous masonry. For the implementation of the shear tests two wall openings are required, whereby the original wall geometry changes and as a consequence a higher applied load is generated in the range of the experiment. This unwanted load increases the calculated maximum shear capacity, whereby it must be reduced at the experiment. In order to compare the calculated compressive load with a linear load distribution over the entire length of the wall, a reduction factor is calculated with a RFEM calculation. By using a calculation with the program RFEM this difference can be clarified (homogeneous shear wall):
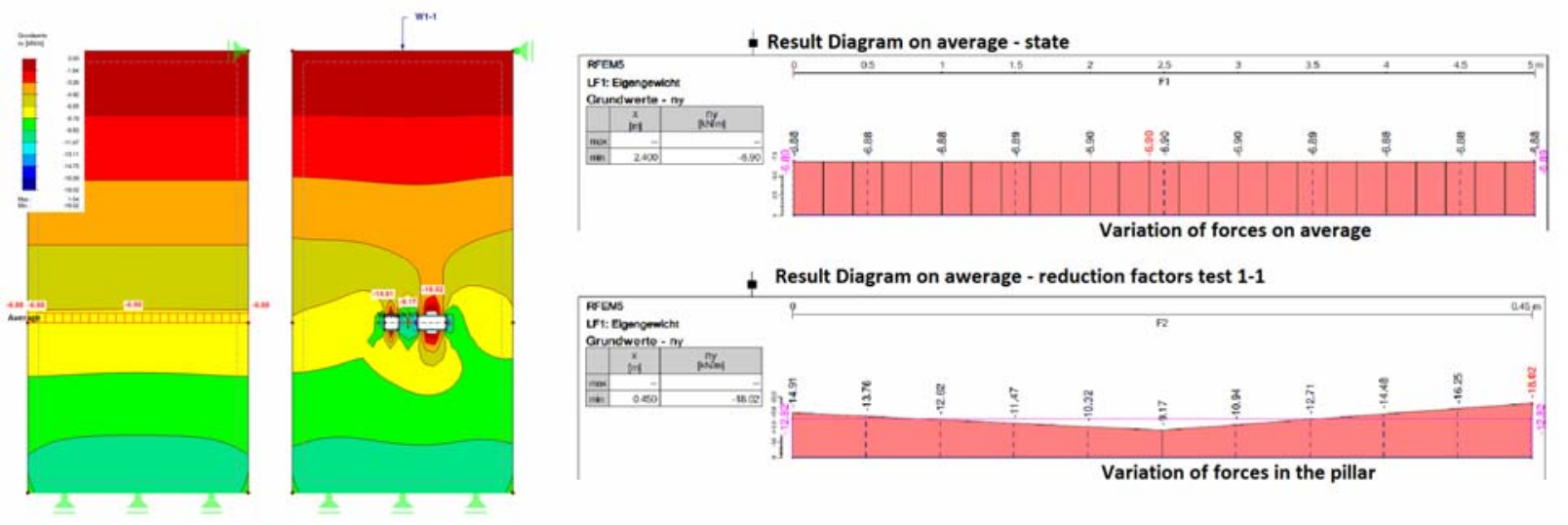

Figure 9: Comparative inventory to breadboard and force behaviour in the average and pillar (right)

Through the adjacent wall openings ("windows") the load on the remaining brick pillars will increase. The comparison of the two different models results in a difference of $5.93 \mathrm{kN} / \mathrm{m}^{2}$, resulting in a reduction factor of 1.86 . For the analysis the reduction factor has been recalculated using the opening geometries for each trial.

Table 2. Calculated reduction factors

\begin{tabular}{|c|c|c|}
\hline Wall with openings & $\mathbf{K N} / \boldsymbol{m}$ & Reduction factor \\
\hline W1-1 & 12.82 & 1.86 \\
\hline W1-2 & 11.40 & 1.65 \\
\hline W1-3 & 11.41 & 1.66 \\
\hline W1-4 & 11.35 & 1.65 \\
\hline
\end{tabular}




\begin{tabular}{|l|l|l|}
\hline W2-2 & 10.98 & 1.59 \\
\hline W2-3 & 11.40 & 1.65 \\
\hline W2-4 & 10.76 & 1.56 \\
\hline W3-2 & 10.55 & 1.53 \\
\hline W3-3 & 10.66 & 1.55 \\
\hline W3-4 & 11.38 & 1.65 \\
\hline W4-2 & 11.25 & 1.63 \\
\hline W5-4 & 11.21 & 1.63 \\
\hline W6-4 & 12.10 & 1.76 \\
\hline
\end{tabular}

\section{Compressive loaded theory}

Theoretical compressive load is referred to at this point as the linear calculation of compressive load, in context of the wall height above the trial and the dead weight of the wall. From the linear relationship between wall geometry (wall height above) and the dead weight of the wall, a value for the maximum shear capacity of an intermediate wall can be quickly calculated. In order to compare this value with the experiments, it is necessary to correct the experimental results by the reduction factors described in section 6 .

\section{Results and conclusion}

As variations due to the different mortar compressive strengths in the test results might occur, it is necessary to determine in each case the associated material parameters in the individual experiments. In the thesis of Mr Bernhard Nowak [2] the exact procedure for the determination of these values is documented and illustrated.

Table 3: Mortar compressive strength of the test sites $\left[\mathrm{N} / \mathrm{mm}^{2}\right]$

\begin{tabular}{|c|c|c|c|c|}
\hline Wall & $\begin{array}{c}\mathbf{1 .} \\
\text { Floor }\end{array}$ & $\begin{array}{c}\mathbf{2 .} \\
\text { Floor }\end{array}$ & $\begin{array}{c}\mathbf{3 .} \\
\text { Floor }\end{array}$ & $\begin{array}{c}\mathbf{4 .} \\
\text { Floor }\end{array}$ \\
\hline 1 & 0.88 & 1.27 & 1.25 & 1.06 \\
\hline 2 & 1.16 & 1.09 & 1.22 & 1.19 \\
\hline 3 & - & 1.15 & 0.93 & 1.03 \\
\hline 4 & - & 1.02 & - & - \\
\hline 5 & - & - & - & 1.04 \\
\hline 6 & - & - & - & 0.94 \\
\hline
\end{tabular}


As can be seen from Table 3, all the values are between 0.88 and $1.27 \mathrm{~N} / \mathrm{mm}^{2}$. An average compressive strength of mortar $1.07 \mathrm{~N} / \mathrm{mm}^{2}$ could be calculated using the regression curve of all sample points. In all experiments, it was found that the mortar joint fails after a displacement of approximately two to four millimetres. This criterion is of great importance with regard to the design of alternative measures (substitutions and earthquake stiffeners of steel or reinforced concrete). If the theme of the horizontal displacement of intermediate walls is examined in a further scientific work, which remain at the Institute for Building Construction at the Technical University of Vienna, our data and test charts can be used as an additional resource.

By occurring load on the mortar joints (load of the wall above it) the maximum limit shear capacity is greatly affected. Therefore, this assumption is of great importance at a theoretical calculation. More compressive load means that the wall accordingly accommodates larger horizontal force (see the formula under point 6). From this relation it may be pre assumed that the lower floors higher horizontal forces can be absorbed (more compressive load, since a higher wall is bricked up about it). In the experiments it was found that these previously calculated results (calculation of the theoretical compressive load) were only partially met. In the evaluation of all tests it was found that the experimental results from W1-1, W1-4 and W2-3 do not coincide with the expected values or the values calculated in RFEM. When comparing the remaining tests, a relatively acceptable deviation could be found. At this point again the reduction factor should be mentioned. By making the holes in a continuous homogeneous surface / wall, load shifts occur. The results are higher compressive stresses in the pillar, which is claimed by the experiment. This phenomenon could be confirmed by means of a RFEM calculation. Since this factor varies depending on the experimental geometry, it was calculated in point 6 of the experimental setup for all test sites. The top two floors have a higher superimposed load, than the theoretical calculation showed in advance. On the second floor a relatively good agreement with the theoretical compressive load was found.

Table 4: Comparison $\mathrm{N}_{\mathrm{Vk}}$ with $\mathrm{N}_{\mathrm{Vk}-\mathrm{A}}[\mathrm{kN} / \mathrm{m}]$

\begin{tabular}{|c|c|c|c|c|c|c|c|c|}
\hline & \multicolumn{2}{|c|}{ 1. Floor } & \multicolumn{2}{c|}{ 2. Floor } & \multicolumn{2}{c|}{ 3. Floor } & \multicolumn{2}{c|}{ 4. Floor } \\
\hline Wall & $\mathrm{N}_{\mathrm{Vk}-\mathrm{A}}$ & $\mathrm{N}_{\mathrm{Vk}}$ & $\mathrm{N}_{\mathrm{Vk}-\mathrm{A}}$ & $\mathrm{N}_{\mathrm{Vk}}$ & $\mathrm{N}_{\mathrm{Vk}-\mathrm{A}}$ & $\mathrm{N}_{\mathrm{Vk}}$ & $\mathrm{N}_{\mathrm{Vk}-\mathrm{A}}$ & $\mathrm{N}_{\mathrm{Vk}}$ \\
\hline 1 & 52.08 & 39.09 & 22.09 & 27.09 & 19.12 & 17.03 & -2.25 & 6.67 \\
\hline 2 & - & - & 32.59 & 28.32 & 46.43 & 17.14 & 21.05 & 6.60 \\
\hline 3 & - & - & 24.50 & 27.00 & 19.43 & 19.07 & 17.93 & 6.85 \\
\hline 4 & - & - & 29.26 & 29.79 & - & - & - & - \\
\hline 5 & - & - & - & - & - & - & 11.43 & 6.94 \\
\hline 6 & - & - & - & - & - & - & 9.98 & 6.60 \\
\hline
\end{tabular}


Comparison $\mathbf{N}_{\mathrm{vk}}-\mathbf{N}_{\mathrm{vk}-\mathrm{A}}$

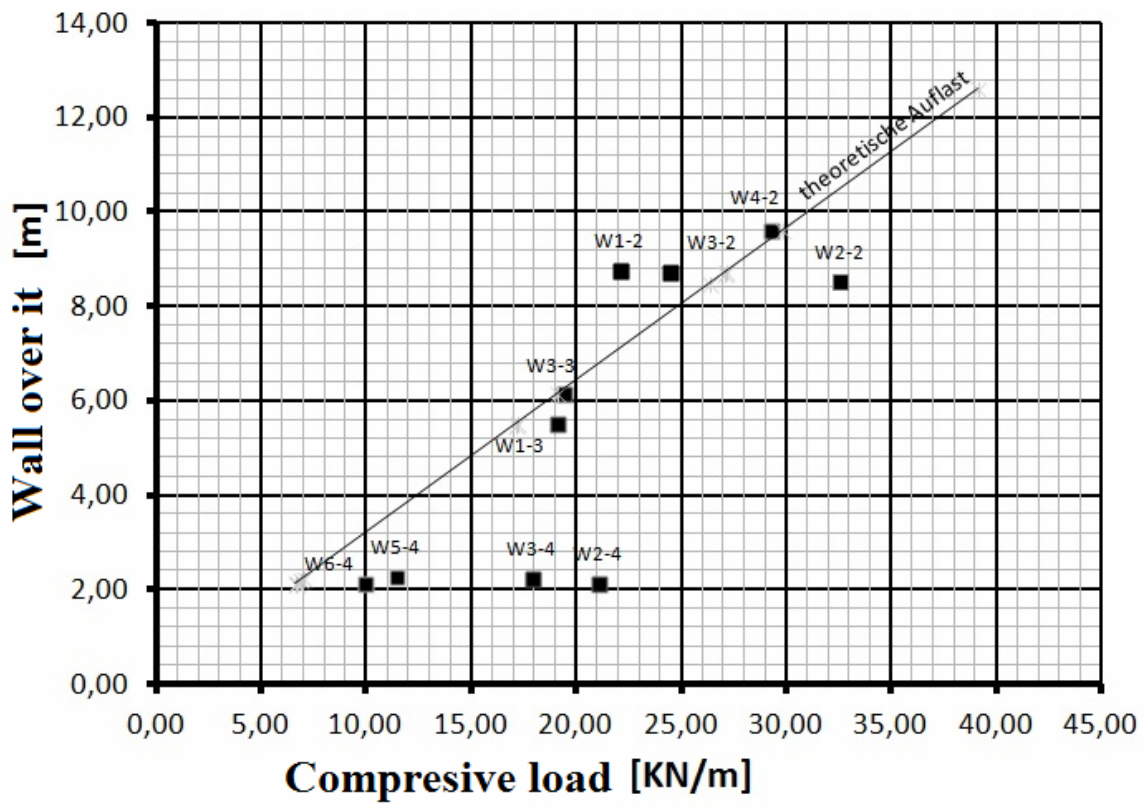

Figure 12: Comparison with $\mathrm{N}_{\mathrm{Vk}}-\mathrm{N}_{\mathrm{Vk}}-\mathrm{A}[\mathrm{kN} / \mathrm{m}]$

When comparing the compressive load from the experiments with the RFEM calculation a better it better match was found than in the theoretical compressive load. Doors lead to changes in the pressure distribution, whereby the applied load can be calculated better than the theoretical compressive load. From this conclusion follows that in calculating the shear resistance of an intermediate wall always at least one RFEM model of the entire intermediate walls has to be created (over the entire existing height). On the top floor however the calculation by the RFEM program are not reflecting the tests values (similar to the theoretical compressive load).

Table 5: Comparison $\mathrm{N}_{\mathrm{Vk}-\mathrm{V}}$ with $\mathrm{N}_{\mathrm{Vk}-\mathrm{Rf}}[\mathrm{kN} / \mathrm{m}]$

\begin{tabular}{|c|c|c|c|c|c|c|c|c|}
\hline & \multicolumn{2}{|c|}{ 1. Floor } & \multicolumn{2}{c|}{ 2. Floor } & \multicolumn{2}{c|}{ 3. Floor } & \multicolumn{2}{c|}{ 4. Floor } \\
\hline Wall & $\mathrm{N}_{\mathrm{Vk}-\mathrm{V}}$ & $\mathrm{N}_{\mathrm{Vk}-\mathrm{Rf}}$ & $\mathrm{N}_{\mathrm{Vk}-\mathrm{V}}$ & $\mathrm{N}_{\mathrm{Vk}-\mathrm{Rf}}$ & $\mathrm{N}_{\mathrm{Vk}-\mathrm{V}}$ & $\mathrm{N}_{\mathrm{Vk}-\mathrm{Rf}}$ & $\mathrm{N}_{\mathrm{Vk}-\mathrm{V}}$ & $\mathrm{N}_{\mathrm{Vk}-\mathrm{Rf}}$ \\
\hline 1 & 96.91 & 65.13 & 36.55 & 40.92 & 31.67 & 26.26 & -3.17 & 9.58 \\
\hline 2 & - & - & 51.94 & 42.88 & 76.83 & 29.32 & 32.88 & 10.93 \\
\hline 3 & - & - & 37.52 & 49.29 & 30.05 & 31.84 & 29.61 & 9.66 \\
\hline 4 & - & - & 47.77 & 47.99 & - & - & - & - \\
\hline 5 & - & - & - & - & - & - & 18.60 & 11.82 \\
\hline 6 & - & - & - & - & - & - & 17.53 & 12.79 \\
\hline
\end{tabular}




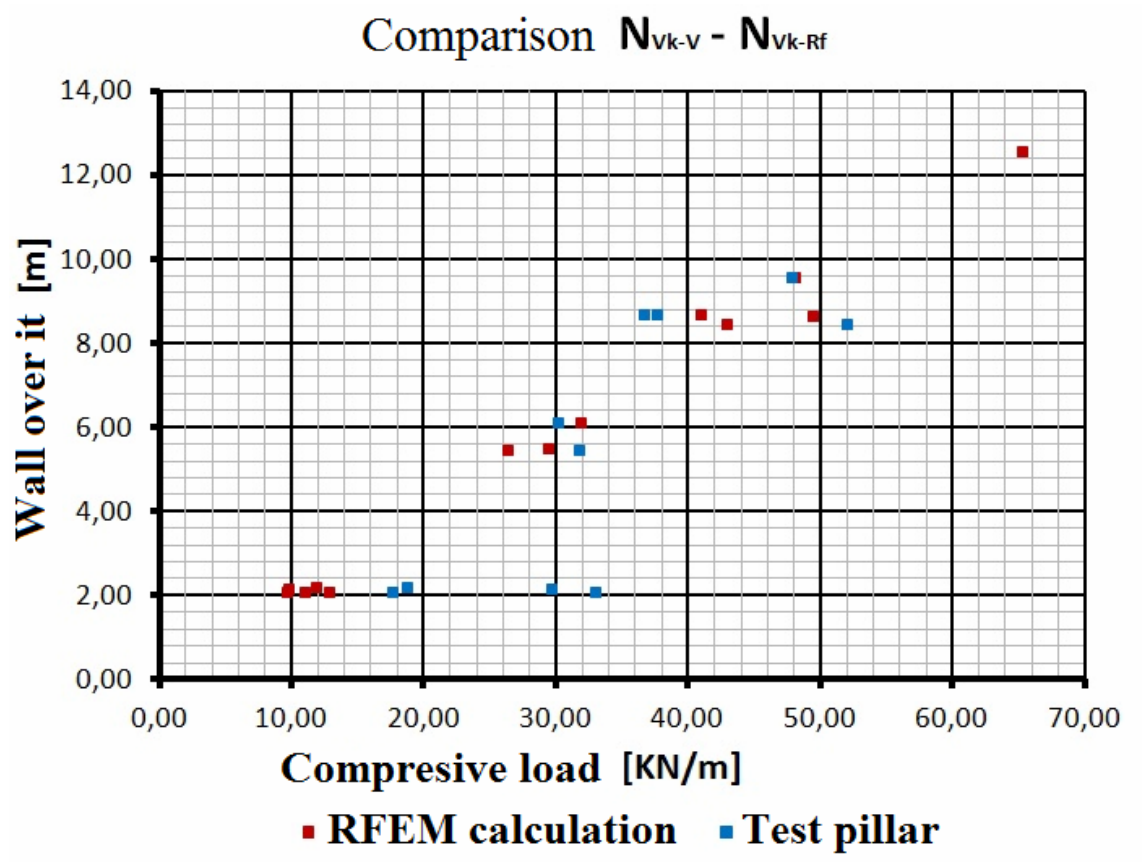

Figure 13: Comparison $\mathrm{N}_{\mathrm{VK}-\mathrm{V}}$ with $\mathrm{N}_{\mathrm{VK}-\mathrm{Rf}}[\mathrm{kN} / \mathrm{m}]$

\section{References}

[1] Günther Achs, Helmut Wenzel Earthquake (2011). Vienna Basin: assessment, risk, location risk, VCE Holding GmbH, Wien 2011

[2] Thesis at the Vienna University of Technology Bernhard Nowak: thrust bearing capability of stiffening, brick intermediate walls; Part 1 - Material parameter study of an existing building, Vienna 2013

[3] ÖNORM EN 1996-1-1 2009-11-15 Design of masonry structures - General Rules for reinforced and unreinforced masonry

[4] ÖNORM B 1996-1-1 2009-03-01 Design of masonry structures - General rules for reinforced and unreinforced masonry

[5] ONR 24009: Assessment of the sustainability of existing buildings, Austrian Standards Institute Edition 2013-05-01

[6] Rudolf Ahnert, Karl Heinz Krause. (2009). Typische Baukonstruktionen von 1860 bis 1960 Band 1, 7. Auflage

[7] Günther Achs, Helmut Wenzel. (2011). Erdbeben im Wiener Becken: Beurteilung, Gefährdung, Standortrisiko, VCE Holding GmbH, Wien 2011

[8] Hans Bobek, Elisabeth Lichtenberger. (1966). Wien Bauliche Gestalt und Entwicklung seit der Mitte des 19. Jahrhunderts, Böhlau 1966

[9] Interdisziplinäre Seminararbeit der TU Wien: Philipp Löffler und Bernhard Nowak Verbindung der lastableitenden Bauteile in Gründerzeithäusern, 2013

[10] Scheidegger Fritz. (1994). Aus der Geschichte der Bautechnik - Band1: Grundlagen, Birkhäuser Verlag, Basel Boston Berlin, 2., korrigierte Auflage 1994 